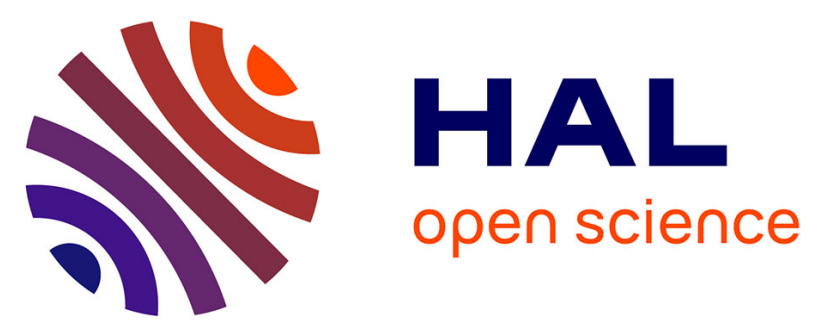

\title{
Does obstructive sleep apnea affect exercise capacity and the hemodynamic response to exercise? An individual patient data and aggregate meta-analysis
}

Mathieu Berger, Christopher E. Kline, Felipe X. Cepeda, Camila F. Rizzi, Céline Chapelle, Silvy Laporte, David Hupin, Jérémy Raffin, Frédéric Costes, Trent A. Hargens, et al.

\section{To cite this version:}

Mathieu Berger, Christopher E. Kline, Felipe X. Cepeda, Camila F. Rizzi, Céline Chapelle, et al.. Does obstructive sleep apnea affect exercise capacity and the hemodynamic response to exercise? An individual patient data and aggregate meta-analysis. Sleep Medicine Reviews, 2019, 45, pp.42 - 53. 10.1016/j.smrv.2019.03.002 . hal-03484475

\section{HAL Id: hal-03484475 \\ https://hal.science/hal-03484475}

Submitted on 20 Dec 2021

HAL is a multi-disciplinary open access archive for the deposit and dissemination of scientific research documents, whether they are published or not. The documents may come from teaching and research institutions in France or abroad, or from public or private research centers.
L'archive ouverte pluridisciplinaire HAL, est destinée au dépôt et à la diffusion de documents scientifiques de niveau recherche, publiés ou non, émanant des établissements d'enseignement et de recherche français ou étrangers, des laboratoires publics ou privés.

\section{(ㅇ)(1) $\$$}

Distributed under a Creative Commons Attribution - NonCommerciall 4.0 International 
Does obstructive sleep apnea affect exercise capacity and the hemodynamic response to exercise? An individual patient data and aggregate meta-analysis

Mathieu Berger, ${ }^{1,2}$ Christopher E. Kline,${ }^{3}$ Felipe X. Cepeda,${ }^{4}$ Camila F. Rizzi, ${ }^{5}$ Céline Chapelle, ${ }^{6}$ Silvy Laporte, ${ }^{6}$ David Hupin, ${ }^{1,2}$ Jérémy Raffin, ${ }^{1,2}$ Frédéric Costes, ${ }^{7}$ Trent A. Hargens, ${ }^{8}$ Jean-Claude Barthélémy, ${ }^{1,2, *}$ Frédéric Roche. ${ }^{1,2, *}$

${ }^{1}$ SNA-EPIS Laboratory, EA 4607, University of Lyon, University Jean Monnet Saint-Etienne, France;

${ }^{2}$ Department of Clinical and Exercise Physiology, University Hospital of Saint-Etienne, France;

${ }^{3}$ Department of Health and Physical Activity, University of Pittsburgh, Pittsburgh, PA, United States; iste?

${ }^{4}$ Heart Institute (InCor), University of São Paulo Medical School, São Paulo, Brazil;

${ }^{5}$ Cardiology Discipline, Medicine Department, Universidade Federal de Sao Paulo, Sao Paulo, Brazil;

${ }^{6}$ INSERM, UMR 1059, SAINBIOSE, Dysfonction Vasculaire et Hémostase, Université Jean Monnet, Saint-Etienne, France ;

${ }^{7}$ Department of Physiology, University Hospital Gabriel Montpied, Clermont-Ferrand, France;

${ }^{8}$ Human Performance Laboratory, Department of Kinesiology, James Madison University, Harrisonburg, VA, United States. 
*Both last authors share senior authorship.

Corresponding author: Mathieu Berger, CHU Saint-Etienne, Hôpital Nord, Centre VISAS, EA SNA EPIS 4607, Université de Lyon, Université Jean Monnet, 42055 Saint-Etienne Cedex 2, France.

Tel: +33 477829 014; Fax: +33 477829 110; E-mail: mathieuberger@ outlook.com

Conflicts of interest: The authors have no conflict of interest to declare

Funding sources: FXC was supported by \#2015/17533-6 and \#2016/16831-7, São Paulo Research Foundation (FAPESP) and Coordenação de Aconselhamento de Pessoal de Nível Superior (CAPES). 


\section{SUMMARY}

Obstructive sleep apnea (OSA) has been linked to altered cardiovascular response to exercise. A systematic review and individual patient data (IPD) meta-analysis were conducted to assess whether OSA patients present reduced exercise capacity. PubMed, Embase and Web of Science were searched until September 2018. Studies which performed sleep recording in both OSA patients and controls and measured maximal oxygen consumption $\left(\mathrm{VO}_{2 \text { peak }}\right)$ via a maximal exercise test were included. IPD were provided for 5 trials upon the 18 eligible $(\mathrm{N}=289)$ and a two-stage IPD meta-analysis model was used, allowing to standardize the apnea cutoff and adjust for confounders. IPD meta-analysis demonstrated that moderate to severe OSA patients had similar $\mathrm{VO}_{2 \text { peak }}$ (mean difference: $-1.03 \mathrm{~mL} \cdot \mathrm{kg}^{-1} \cdot \mathrm{min}^{-1}$; $95 \% \mathrm{CI}$ : -3.82 to $1.76 ; \mathrm{p}=0.47$ ) and cardiovascular response to exercise compared to mild or non-OSA patients. By contrast, aggregate data (AD) meta-analysis including the 13 trials for which IPD were unavailable $(\mathrm{N}=605)$ revealed that $\mathrm{VO}_{\text {2peak }}$ was reduced in OSA patients compared to controls (mean difference: $-2.30 \mathrm{~mL} \cdot \mathrm{kg}^{-1} \cdot \mathrm{min}^{-1}$; $95 \%$ CI: -3.96 to -0.63 ; $\left.\mathrm{p}<0.001\right)$ with high heterogeneity. In conclusion, IPD meta-analysis suggests that $\mathrm{VO}_{2 \text { peak }}$ and the cardiovascular response to exercise are preserved in moderate to severe OSA patients while AD meta-analysis suggests lower $\mathrm{VO}_{2 \text { peak }}$ in severe OSA.

Keywords: meta-analysis; individual patient data; aggregate data; obstructive sleep apnea; exercise capacity; peak oxygen consumption; cardiopulmonary exercise test. 


\section{LIST OF ABBREVIATIONS}

$\mathrm{AD}$ : aggregate data

AHI: apnea-hypopnea index

BMI: body mass index

CPET: cardiopulmonary exercise test

DBP: diastolic blood pressure

HR: heart rate

HRR-1: one-minute post-exercise heart rate recovery

IPD: individual patient data

MD: mean difference

NOS: Newcastle-Ottawa Scale

OSA: obstructive sleep apnea

$\mathrm{SaO}_{2 \text { min: }}$ nadir oxygen saturation

SBP: systolic blood pressure

$\mathrm{VO}_{2 \text { peak: }}$ peak oxygen uptake 


\section{INTRODUCTION}

Obstructive sleep apnea (OSA) is a chronic disorder characterized by repetitive episodes of partial or complete airway obstruction [1]. Although recent data suggest that this form of sleepdisordered breathing is highly prevalent in the general population, occurring in one in four women and one in two men [2], a significant proportion of moderate to severe OSA patients are undiagnosed [3]. Repeated hypoxemia and fragmented sleep induced by each obstruction increase sympathetic activity to peripheral blood vessels [4-6] and promote oxidative stress [7, 8], inflammation [8-11] and endothelial dysfunction [8, 12, 13]. These alterations lead to numerous adverse cardiovascular consequences including systemic hypertension, arrhythmia, and acute cardiovascular and cerebrovascular events [14-16].

Despite the ample evidence of cardiovascular risk in OSA patients, little is known about the cardiopulmonary response to exercise in these patients. The existing literature shows conflicting results. Some studies have shown that OSA impairs exercise capacity as reflected by peak oxygen uptake $\left(\mathrm{VO}_{2 \text { peak }}\right)$ [17-25], while others have suggested that exercise capacity is preserved [26-37]. Additionally, some published reports note an altered hemodynamic response in OSA regarding higher peak diastolic blood pressure (DBP) [20, 26, 29, 31], lower oxygen pulse $[18,31]$, lower peak heart rate (HR) [23, 29], and blunted one-minute post-exercise heart rate recovery (HRR-1) [17, 23, 24, 30, 32, 33, 36]; others, however, found no significant difference in these parameters between those with and without OSA [22, 30, 32, 33, 35, 36].

Recently, Mendelson et al. published a systematic review and meta-analysis on maximal exercise capacity in patients with OSA [38]. Interestingly, they found that mean $\mathrm{VO}_{2 \text { peak }}$ was significantly lower in patients with OSA compared to controls. However, these authors reported a high level of heterogeneity in their meta-analysis, which may be explained by several methodological limitations including unequal allocation within studies [24, 26, 28, 29, 33], small sample size [20, 26, 30], and absence of sleep-recording in controls [20, 24, 26]. 
Moreover, comparison between trials appears difficult since the apnea severity threshold for OSA categorization fluctuated between 5 and 30 events/h according to the study. Thus, whether OSA patients present impaired exercise capacity and specific hemodynamic response to exercise remain unclear.

We therefore initiated a systematic review and meta-analysis of both individual patient data (IPD) and aggregate data (AD) to determine whether exercise capacity is altered in moderate to severe OSA patients. A combination of results of the different trials available in an IPD metaanalysis increases statistical power, reduces heterogeneity and allows us to transform data to a common OSA threshold in the present study. The secondary objective was to evaluate whether OSA patients have an altered hemodynamic response to exercise.

\section{METHODS}

\section{Identification of studies}

Nonrandomized studies were first identified in March 2017 from PubMed, Embase and Web of Science using the following keywords: ("Sleep Apnea, Obstructive" [Mesh] OR "Sleep Apnea Syndromes" [Mesh]) AND "Exercise test" [Mesh], limited to articles written in English and dealing with human subjects. The search was updated in September 2018. The reference lists of selected studies were reviewed to identify trials missed out by electronic search. Two investigators (MB and JCB) selected studies independently and any disagreement was resolved by consensus with a third reviewer (FR).

\section{Inclusion and exclusion criteria}

Inclusion criteria were the following: (1) case-control or cross-sectional study including adult participants (age >18 y); (2) polysomnography or polygraphy performed in OSA patients and 
controls; (3) exercise capacity measured via a symptom-limited maximal cardiopulmonary exercise test (CPET).

Articles were excluded if: (1) subjects were diagnosed with heart failure, atrial fibrillation, neuromuscular disorders, chronic pulmonary disease, alcohol or other drug abuse, or pregnancy; (2) patients were previously treated for OSA by continuous positive airway pressure, mandibular advanced device or upper airway surgery, as well as for sleep disorders other than OSA, including central sleep apnea, circadian rhythm disorder, periodic leg movements, insomnia, or narcolepsy; (3) patients were treated with ß-blocker medication; (4) no control group was established for comparison; (5) maximal oxygen consumption was measured indirectly; (6) more than one month had elapsed between sleep recording and CPET.

\section{Data collection and management}

Each corresponding author of the selected articles was contacted and invited to provide IPD for the following variables: patient characteristics (i.e., age, height, weight, BMI, sex, AHI, nadir oxygen saturation $\left[\mathrm{SaO}_{2 \mathrm{~min}}\right]$, treated hypertension) and CPET data (i.e., type of protocol, $\mathrm{VO}_{2 \text { peak }}\left[\right.$ in $\mathrm{mL} \cdot \mathrm{kg}^{-1} \cdot \mathrm{min}^{-1}$ ], resting and peak HR, HRR-1, peak systolic blood pressure [SBP] and DBP). In case of non-reply, corresponding authors were contacted a second time and alternative email contact was searched. For studies whose corresponding authors did not provide IPD, the following $\mathrm{AD}$ were collected from relevant studies: first author's name, year of publication, journal, number of participants, percentage of males, type of sleep recording, OSA threshold, CPET modality (ergocycle or treadmill) and type of protocol, mean age, body mass index (BMI), apnea-hypopnea index (AHI), and CPET data available with standard deviations for OSA patients and controls. 


\section{Study quality assessment}

The quality of the studies included was assessed by MB and JCB with a modified version of the Newcastle-Ottawa Scale (NOS) previously adapted by Mendelson et al. [38, 39]. The scale score varied from 0 to 8 and included three dimensions: selection, comparability and exposure. Disagreements on scale scores were resolved by consensus.

\section{Risk of bias}

We performed consistency checks on all IPD. Baseline characteristics, method of analysis and results were compared with the published information. Any discrepancies, missing data, obvious errors, and inconsistencies between variables or outlying values were queried and rectified as necessary with input from the original authors.

\section{OSA cutoff}

OSA was assessed using polysomnography or polygraphy in both OSA and control groups. For the AD meta-analysis, the original studies' OSA and control cutoffs were kept. For the IPD analysis, OSA was recategorized based on an $\mathrm{AHI} \geq 15$ events/h, corresponding to a commonly used cutoff associated with higher cardiovascular and cerebrovascular risk [40] and controls were defined by an $\mathrm{AHI}<15$.

\section{Outcome of interest}

Exercise capacity, the prespecified primary outcome of interest in AD and IPD meta-analysis, was assessed by $\mathrm{VO}_{2 \text { peak }}$ during CPET and expressed in $\mathrm{mLkg}^{-1} \cdot \mathrm{min}^{-1}$. Secondary prespecified outcomes of interest in the IPD meta-analysis included percentage predicted $\mathrm{VO}_{2 \text { peak }}$, agepredicted peak HR, HR reserve (calculated as peak HR - resting HR), HRR-1, peak SBP and DBP. To standardize predicted $\mathrm{VO}_{2 \text { peak }}$ across studies in the IPD meta-analysis, the Wasserman 
and Hansen equations were used according to the EACPR/AHA Scientific Statement on Exercise testing [41]. The Jones equation (i.e., $210-[0.65 \mathrm{x}$ age $]$ ) was used to calculate agepredicted peak HR [42].

\section{Statistical analysis}

The meta-analysis was performed in accordance with the PRISMA-IPD Statement [43] (cf. online supplement Table S1 for PRISMA-IPD checklist) and registered in PROSPERO (CRD42019118730). A two-stage IPD meta-analysis model was used to compare between groups in terms of $\mathrm{VO}_{2 \text { peak }}$ (expressed in $\mathrm{mLkg}^{-1} \cdot \mathrm{min}^{-1}$ and in percentage predicted), peak HR, HR reserve, HRR-1, peak SBP, and DBP. Briefly, we created summary statistics out of IPD with adjustment for confounding factors including age, BMI, gender and treated hypertension (stage 1). Then we combined the mean difference (MD) using a DerSimonian and Laird random effect model since we assume that the true effect size could vary from study to study (stage 2). To assess potential risk of bias associated with nonavailability of IPD and to compare results from analyses that include IPD and non-IPD studies, a two-stage meta-analysis approach was used to combine the available AD with the IPD for the primary outcome without adjustment for cofounding factors [44]. Heterogeneity was assessed by the $\mathrm{I}^{2}$ test and Cochran's $Q$ test. To check for publication bias, funnel plots of effect size and standard error were constructed. The presence of asymmetry in the funnel plot was assessed using Egger's test [45]. To investigate the heterogeneity, a sensitivity analysis was performed using sub-groups according to OSA definition based on the AHI threshold chosen by authors. Statistical analysis was performed with IBM SPSS Statistics version 24.0 for Macintosh (IMB Corp., Armonk, N.Y., USA) for the stage 1 statistics and with Comprehensive Meta-Analysis software (V.3.3.070 - November 2014, Biostat: Englewood, USA) for the stage 2 analysis. A p-value of less than 0.05 was 
considered statistically significant, except for the Cochran's Q and Egger's tests in which the p-value was set at 0.1 .

\section{RESULTS}

\section{Characteristics of the included studies}

A total of 666 studies were identified (140 from PubMed, 323 from Embase, and 203 from Web of Science) (Fig. 1). Among them, 17 studies met inclusion criteria and were included in the meta-analysis. Data from the screening of the EXESAS study (ClinicalTrials.gov: NCT02463890), which focused on the benefit of exercise in obstructive sleep apnea [46], were also added. Thus, IPD were sought for 18 studies (N=894) and obtained from five studies (28\% of all studies; N=289). Reasons for why IPD were not provided IPD are detailed in Fig. 1. For the 13 studies for which IPD were not provided, AD were available for the primary outcome and used in sensitivity analyses $(\mathrm{N}=605)$.

Two studies included in the IPD meta-analysis were conducted in the United States [30, 33], two in Brazil [32, 34] and one in Europe [46]. Overall, four of the studies included in the AD meta-analysis were conducted in the United States [17, 22, 29, 47], four in Brazil [31, 35, 48, 49], four in Europe [28, 36, 37], and two in Taiwan [18, 23].

All participants from the five IPD trials were provided by authors and included in the IPD meta-analysis. No significant issues were identified in checking IPD. In the 5 IPD studies, mean age was $49.7 \pm 15.2$ y (range from 18 to 80 ), and mean BMI was $29.0 \pm 5.5 \mathrm{~kg} \cdot \mathrm{m}^{-2}$ (range from 18.1 to 50.7) (Table 1). A majority of the participants (60.7\%) were male and $23 \%$ were treated for hypertension. For $\mathrm{AD}$, the mean age of the participants ranged from $30 \pm 13$ to $71 \pm 7$ $\mathrm{y}$, and mean BMI from $25.9 \pm 2.6$ to $50.5 \pm 9.4 \mathrm{~kg} \cdot \mathrm{m}^{-2}$ (Table 1). The OSA threshold based on AHI varied from $\geq 5$ to $>30$ events/h across studies. Similarly, the control AHI threshold varied from $<5$ to $\leq 30$ 
All studies included in the IPD meta-analysis were of good quality with at least 6 stars on the NOS, while 7 additional studies included in the AD meta-analysis were of good quality and 6 trials presented lower quality (i.e., 4 or 5 stars) (Table 2).

\section{Main outcome}

No significant difference in $\mathrm{VO}_{2 \text { peak }}$, expressed in $\mathrm{mLkg}^{-1} \cdot \mathrm{min}^{-1}$, was observed between OSA patients (AHI $\geq 15$ events/h) and controls (AHI $<15$ events/h) in the IPD meta-analysis $(\mathrm{MD}=$ $-1.03 \mathrm{~mL} \mathrm{~kg}^{-1} \cdot \mathrm{min}^{-1} ; 95 \% \mathrm{CI}:-3.82$ to $\left.1.76 ; \mathrm{p}=0.47\right)$ and heterogeneity across studies was low $\left(\mathrm{I}^{2}=0 \% ; \mathrm{p}=0.893\right)$ (Figure 2). In the $\mathrm{AD}$ meta-analysis, mean $\mathrm{VO}_{2 \text { peak }}$ was significantly lower in OSA patients compared to controls $(\mathrm{MD}=-2.30 ; 95 \% \mathrm{CI}:-3.96$ to $-0.63 ; \mathrm{p}=0.01$; Figure 2 ) and heterogeneity was high $\left(\mathrm{I}^{2}=83 \%\right.$; $\mathrm{p}<0.0001$ for Cochran's $Q$ test $)$. When including $\mathrm{AD}$ with IPD, $\mathrm{VO}_{2 \text { peak }}$ was significantly lower in OSA patients compared to controls $(\mathrm{MD}=-1.96 ; 95 \%$ CI: -3.40 to $-0.53 ; \mathrm{p}=0.01$; Figure 2$)$ and heterogeneity was high $\left(\mathrm{I}^{2}=77 \% ; \mathrm{p}<0.0001\right.$ for Cochran's $Q$ test). The funnel plot did not identify evident publication bias, either when including or excluding the AD studies (Figure 3) and Egger's test showed no selective reporting bias $(\mathrm{p}=0.43)$.

The subgroup analysis conducted with AD studies did not show significant difference in $\mathrm{VO}_{2 \text { peak }}$ when the OSA definition was based on an AHI $>5,10$ or 15 (Figure 4). The only significant difference was observed for an AHI cutoff of 30 (MD $=-4.27 ; 95 \%$ CI: -7.56 to 0.96; $\mathrm{p}=0.01 ;$ Figure 4).

In IPD meta-analysis, $\mathrm{VO}_{2 \text { peak }}$ remained nonsignificant between OSA patients and controls after adjustment for age, gender and hypertension $\left(\mathrm{p}=0.35\right.$; Figure 5A.). Heterogeneity was low $\left(\mathrm{I}^{2}\right.$ $=0 \% ; \mathrm{p}=0.973)$.

\section{Secondary outcomes}


In the IPD meta-analysis, mean $\mathrm{VO}_{2 \text { peak, }}$ expressed as percentage predicted did not differ between OSA patients and controls after adjusting for treated hypertension $(\mathrm{MD}=1.30 ; 95 \%$ CI: -4.48 to $7.08 ; \mathrm{p}=0.66$; Figure 5B.). Likewise, peak heart rate, expressed as percentage predicted, was similar between groups after adjustment for sex, hypertension and BMI (MD = $-0.34 ; 95 \%$ CI: -3.50 to $2.82 ; \mathrm{p}=0.83$; Figure $6 \mathrm{~A}$.). HRR-1 was significantly lower in OSA patients compared to controls, even after adjustment for confounders (MD $=-2.79 ; 95 \% \mathrm{CI}$ : 5.18 to $-0.41 ; \mathrm{p}=0.02$; Figure $6 \mathrm{C}$.). No other significant differences were observed between groups for HR reserve, oxygen pulse (Figure 6B-6D), peak SBP, or peak DBP (Figure 7A-7B) during CPET after adjustment for age, sex, hypertension and BMI. Data were homogeneous, except for HRR-1 and oxygen pulse, for which moderate heterogeneity were reported $\left(\mathrm{I}^{2}=51\right.$ and $55 \%$, respectively; $\mathrm{p}<0.1$ for Cochran's $Q$ test). 


\section{DISCUSSION}

\section{Main results}

The IPD meta-analysis, which included 5 trials with a common OSA definition and a total of 289 participants, revealed no significant difference in $\mathrm{VO}_{2 \text { peak }}$ between OSA patients $(\mathrm{AHI} \geq 15$ events per $\mathrm{h})$ and matched controls (AHI $<15$ events per $\mathrm{h})$ with a high degree of homogeneity observed across studies.

By contrast, the AD meta-analysis, which included 13 studies that did not provide IPD, showed that $\mathrm{VO}_{2 \text { peak }}$ was significantly lower by $2.3 \mathrm{~mL} \cdot \mathrm{kg}^{-1} \cdot \mathrm{min}^{-1}$ in OSA patients, which was quite similar to the $-2.7 \mathrm{mLkg}^{-1} \cdot \mathrm{min}^{-1}$ recently reported by Mendelson et al. in an AD metaanalysis including 19 trials [38]. In contrast to their AD meta-analysis, we excluded four studies from the AD meta-analysis which did not assess the absence of OSA in controls via polygraphy or polysomnography and which may have attenuated the mean difference $[20,24,26,27]$. Moreover, one study was not included [50] since the ClinicalTrials number was identical to a study already included in the meta-analysis [23] and another study was excluded [51] since the population characteristics were similar to those from a study previously published by the same author the same year [36]. In addition, three studies not reported by Mendelson et al. were included in the present meta-analysis [35, 36, 49]. Despite no evident publication bias was experienced on the funnel plot, the high level of inconsistency assessed though $\mathrm{I}^{2}$ and Cochran's $Q$ test reported and the absence of adjustment for confounders in statistical analyses reduces the confidence of these results $[52,53]$.

When pooling the AD results ( $\mathrm{n}=13$ studies) with the IPD results ( $\mathrm{n}=5$ studies), the overall meta-analysis documented significantly lower $\mathrm{VO}_{2 \text { peak }}$ in OSA patients compared to controls, and heterogeneity remained high $\left(\mathrm{I}^{2}>75 \%\right)$. Interestingly, the AD subgroup analysis seems to show a dose-response relationship in that, as higher the OSA threshold was set, the 
larger the difference in $\mathrm{VO}_{2 \text { peak }}$ between OSA and non-OSA groups. This reduction in VO2peak was only significant for severe OSA (AHI >30) compared to non-OSA.

Concerning the hemodynamic response to exercise, we did not find any difference in age-predicted peak HR, HR reserve, peak oxygen pulse, peak SBP, or peak DBP between those with $\mathrm{AHI} \geq 15$ and those with $\mathrm{AHI}<15$ in the IPD meta-analysis. Only HRR-1 was significantly blunted in OSA patients, as has been previously observed [24, 30, 33, 36]. Thus, this IPD metaanalysis emphasizes a similar hemodynamic response to exercise in OSA patients compared to controls, despite a potential lack of statistical power and some limitations in the studies' heterogeneity which may be explained by the low number of studies included in the IPD metaanalysis (5/18 studies).

\section{Quality of the evidence}

The main strength of this study was the use of IPD from five studies. In addition to allowing us to standardize the apnea threshold across studies, the IPD meta-analysis permitted us to adjust analysis for covariates which should minimize the aggregation bias and reveal the true effect of OSA on exercise capacity, independently of age, sex, BMI or hypertension treatment. In the present IPD meta-analysis, we chose the AHI cutoff at 15 events/h since it corresponds to the threshold from which cardiovascular risk increases in OSA patients $[54,55]$. This may explain the absence of impairment in $\mathrm{VO}_{2 \text { peak }}$ and cardiovascular response to exercise that we observed in our meta-analysis. Indeed, while there is strong evidence that severe OSA is associated with high cardiovascular risk as well as cardiometabolic comorbidities, it appears

less evident for mild OSA $[15,54-56]$. One could hypothesize that only severe OSA is associated with lower exercise capacity when compared with non-OSA as shown by our subgroup analysis according to OSA definition. 
A systematic research was conducted through an extensive database search and all first authors from eligible studies were contacted to provide IPD, thus addressing the concern of a potential selection bias. Another strength was the investigation of the impact of the studies for which IPD were lacking as recommended by the PRISMA-IPD guidelines [43, 44].

\section{Limitations}

The main limitation of the present meta-analysis was the inclusion of only five trials upon 18 eligible trials in the IPD meta-analysis which may have induced an availability bias [44]. However, the impact of availability bias is hard to predict and the overall meta-analysis (pooled IPD and AD) including AD results available cannot fully address this threat.

Although the quality of studies included was high according to the modified NOS scale [39], the evidence for an OSA-related exercise capacity impairment appears largely incomplete to date. Indeed, though the $\mathrm{AD}$ meta-analysis demonstrated significantly lower $\mathrm{VO}_{2 \text { peak }}$ among adults with OSA, the broad variation of OSA severity threshold from one study to another and the lack of adjustment for confounders reduces the confidence of these results. Similarly, the overall meta-analysis should be interpreted with caution due to the 13 heterogenous AD trials which were of a major impact as compared to the 5 IPD trials. It is obvious that it would be better to include more trials in the IPD meta-analysis; however, we were dependent upon the principal investigator to provide IPD. In our opinion, it is higher quality and more suitable to have 5 homogeneous studies with a common pathological definition of OSA than 18 studies with widely varying OSA definitions.

Likewise, it would have been interesting to conduct a subgroup analysis according to non-OSA $(<5$ events/h), mild (5-15 events/h), moderate $(15-30$ events/h) and severe $(>30$ events/h) OSA to further explore the relationship between OSA severity and exercise capacity. 
Unfortunately, the low response rate from authors for sharing their IPD required us to limit our IPD meta-analysis to a dichotomous cutoff.

Another limitation was the unequal allocation between case and controls in six of the 18 studies included in the present meta-analysis [28, 29, 32, 33, 35, 46], with ratios varying from 1.5 case for one control to 6 case for one control, which decreases the statistical power. A third limitation was the use of three different definitions of hypopnea (1999, 2007 and 2012 AASM criteria) across the studies included, which might increase the risk of bias. Indeed, the AASM 2007 criteria [57] are considered more restrictive than the 1999 AASM Chicago criteria [1], while the 2012 AASM criteria [58] are more liberal. Thus, some patients categorized as mild OSA according to the 2007 AASM criteria might be categorized as moderate OSA according to current guidelines. A fourth limitation was the lack of objective measure of physical activity level in the included studies. Whereas it is well known that one's habitual physical activity level influence maximal exercise capacity [59] and recent evidence suggests that adults with OSA are less active than those without OSA [57], none of the studies included matched OSA patients with controls with respect to physical activity measured via accelerometer. Therefore, it cannot be ruled out that the significant difference observed in $\mathrm{VO}_{2 \text { peak }}$ between OSA patients and controls in the $\mathrm{AD}$ meta-analysis may be due, at least in part, to a difference in physical activity level at inclusion. A fifth limitation was the variability of protocol used to evaluate $\mathrm{VO}_{2 \text { peak }}$ across studies. Although all studies included in the metaanalysis performed the same protocol for OSA patients and controls, comparison between studies could be difficult since $\mathrm{VO}_{2 \text { peak }}$ can vary depending on the modality of stress test (ergocycle or treadmill), the workload increment, or the duration of the test [60]. Lastly, women were clearly underrepresented in previous studies, precluding determination of whether OSA affects exercise capacity in men differently than in women. 


\section{Clinical implications}

Although the current individual patient data suggest that OSA per se do not alter the cardiovascular response to exercise, it is important to keep in mind that OSA patients have frequent cardiometabolic comorbidities, including obesity, type 2 diabetes mellitus (T2DM) and hypertension, particularly in severe OSA patients [16, 61, 62]. Thus, even if OSA per se does not alter the cardiovascular response to exercise, the associated comorbidities may favor a lower exercise capacity $[19,63]$. Interestingly, one recent study highlighted that being physically active reduced the risk of developing OSA over a 8- to 9-year follow-up, had a protective effect against T2DM incidence, and was associated with a better cardiometabolic profile [64]. Therefore, prescribing exercise in OSA patients, independently of initial $\mathrm{VO}_{2 \text { peak, }}$ remains strongly recommended and beneficial, notably by improving glucose uptake, insulin sensitivity, blood lipids, and decreasing blood pressure and inflammation [59, 65]. Lastly, beyond the reduced risk of cardiovascular disease and all-cause mortality associated with an increase in $\mathrm{VO}_{2 \text { peak }}[59,63,66]$, increased physical activity will have a clinical impact by reducing OSA severity and daytime symptoms of sleepiness [46, 67, 68].

\section{CONCLUSION}

In conclusion, our IPD meta-analysis suggests that the lower exercise capacity previously documented in OSA patients via $\mathrm{AD}$ meta-analysis is not obvious in moderate to severe OSA as compared to mild or non-OSA. However, subgroup analysis conducted with AD trials suggests that only severe OSA patients had lower $\mathrm{VO}_{2 \text { peak }}$ compared to controls.

Furthermore, the IPD meta-analysis revealed that the cardiovascular response to exercise did not differ between OSA and non-OSA groups, although a moderate to high heterogeneity and risk of bias were reported. Only HRR-1, a measure of autonomic dysfunction, was blunted following maximal exercise in OSA patients compared to controls. Additional high 
quality cross-sectional studies covering the entire spectrum of OSA severity with standardized sleep and exercise test assessments are needed to confirm these results.

\section{Acknowledgements}

We are grateful for the coauthors who made this meta-analysis possible by accepting to share their individual patient data.

\section{Practice Points}

1) The IPD meta-analysis revealed that moderate to severe OSA patients had similar $\mathrm{VO}_{2 \text { peak }}$ to mild and non-OSA controls with low heterogeneity.

2) The $\mathrm{AD}$ and overall meta-analysis showed that OSA is associated with lower $\mathrm{VO}_{2 \text { peak }}$ as compared to controls with high heterogeneity.

3) AD subgroup analysis revealed that only severe OSA is associated with lower $\mathrm{VO}_{2 \text { peak }}$ as compared to controls.

4) The cardiovascular response to exercise is not altered in moderate to severe OSA.

5) Only HRR-1, a measure of autonomic dysfunction, is blunted following maximal exercise test in OSA patients compared to controls

\section{Research Agenda}

Future research should:

1) Standardize apnea severity threshold according to current guidelines;

2) Match controls for comorbidities, including BMI and hypertension, and for physical activity level measured objectively;

3) Explore the influence of sex on $\mathrm{VO}_{2 \text { peak }}$ in OSA patients. 


\section{References}

[1] Sleep-related breathing disorders in adults: recommendations for syndrome definition and measurement techniques in clinical research. The Report of an American Academy of Sleep Medicine Task Force. Sleep. 1999;22:667-89.

[2] Heinzer R, Vat S, Marques-Vidal P, Marti-Soler H, Andries D, Tobback N, et al. Prevalence of sleep-disordered breathing in the general population: the HypnoLaus study. The Lancet Respiratory medicine. 2015;3:310-8.

[3] Young T, Peppard P, Palta M, Hla KM, Finn L, Morgan B, et al. Population-based study of sleep-disordered breathing as a risk factor for hypertension. Arch Intern Med. 1997;157:174652.

[4] Somers VK, Dyken ME, Clary MP, Abboud FM. Sympathetic neural mechanisms in obstructive sleep apnea. J Clin Invest. 1995;96:1897-904.

[5] Narkiewicz K, van de Borne PJ, Montano N, Dyken ME, Phillips BG, Somers VK. Contribution of tonic chemoreflex activation to sympathetic activity and blood pressure in patients with obstructive sleep apnea. Circulation. 1998;97:943-5.

[6] Narkiewicz K, Montano N, Cogliati C, van de Borne PJ, Dyken ME, Somers VK. Altered cardiovascular variability in obstructive sleep apnea. Circulation. 1998;98:1071-7.

[7] Schulz R, Mahmoudi S, Hattar K, Sibelius U, Olschewski H, Mayer K, et al. Enhanced release of superoxide from polymorphonuclear neutrophils in obstructive sleep apnea. Impact of continuous positive airway pressure therapy. Am J Respir Crit Care Med. 2000;162:566-70. [8] Jelic S, Padeletti M, Kawut SM, Higgins C, Canfield SM, Onat D, et al. Inflammation, oxidative stress, and repair capacity of the vascular endothelium in obstructive sleep apnea. Circulation. 2008;117:2270-8. 
[9] Yokoe T, Minoguchi K, Matsuo H, Oda N, Minoguchi H, Yoshino G, et al. Elevated levels of C-reactive protein and interleukin-6 in patients with obstructive sleep apnea syndrome are decreased by nasal continuous positive airway pressure. Circulation. 2003;107:1129-34.

[10] Ohga E, Tomita T, Wada H, Yamamoto H, Nagase T, Ouchi Y. Effects of obstructive sleep apnea on circulating ICAM-1, IL-8, and MCP-1. J Appl Physiol. 2003;94:179-84.

[11] Punjabi NM, Beamer BA. C-reactive protein is associated with sleep disordered breathing independent of adiposity. Sleep. 2007;30:29-34.

[12] Schulz R, Schmidt D, Blum A, Lopes-Ribeiro X, Lucke C, Mayer K, et al. Decreased plasma levels of nitric oxide derivatives in obstructive sleep apnoea: response to CPAP therapy. Thorax. 2000;55:1046-51.

[13] Phillips BG, Narkiewicz K, Pesek CA, Haynes WG, Dyken ME, Somers VK. Effects of obstructive sleep apnea on endothelin-1 and blood pressure. J Hypertens. 1999;17:61-6.

[14] Bradley TD, Floras JS. Obstructive sleep apnoea and its cardiovascular consequences. Lancet. 2009;373:82-93.

[15] Marin JM, Carrizo SJ, Vicente E, Agusti AGN. Long-term cardiovascular outcomes in men with obstructive sleep apnoea-hypopnoea with or without treatment with continuous positive airway pressure: an observational study. Lancet. 2005;365:1046-53.

[16] Somers VK, White DP, Amin R, Abraham WT, Costa F, Culebras A, et al. Sleep apnea and cardiovascular disease: an American Heart Association/American College of Cardiology Foundation Scientific Statement from the American Heart Association Council for High Blood Pressure Research Professional Education Committee, Council on Clinical Cardiology, Stroke Council, and Council on Cardiovascular Nursing. J Am Coll Cardiol. 2008;52:686-717.

[17] Vanhecke TE, Franklin BA, Zalesin KC, Sangal RB, deJong AT, Agrawal V, et al. Cardiorespiratory fitness and obstructive sleep apnea syndrome in morbidly obese patients. Chest. 2008;134:539-45. 
[18] Lin CC, Hsieh WY, Chou CS, Liaw SF. Cardiopulmonary exercise testing in obstructive sleep apnea syndrome. Respir Physiol \& Neurobiol. 2006;150:27-34.

[19] Mansukhani MP, Allison TG, Lopez-Jimenez F, Somers VK, Caples SM. Functional aerobic capacity in patients with sleep-disordered breathing. Am J Cardiol. 2013;111:1650-4. [20] Vanuxem D, Badier M, Guillot C, Delpierre S, Jahjah F, Vanuxem P. Impairment of muscle energy metabolism in patients with sleep apnoea syndrome. Respir Med. 1997;91:5517.

[21] Ucok K, Aycicek A, Sezer M, Genc A, Akkaya M, Caglar V, et al. Aerobic and anaerobic exercise capacities in obstructive sleep apnea and associations with subcutaneous fat distributions. Lung. 2009;187:29-36.

[22] Beitler JR, Awad KM, Bakker JP, Edwards BA, DeYoung P, Djonlagic I, et al. Obstructive sleep apnea is associated with impaired exercise capacity: a cross-sectional study. J Clin Sleep Med. 2014;10:1199-204.

[23] Chien MY, Lee P, Tsai YF, Yang PC, Wu YT. C-reactive protein and heart rate recovery in middle-aged men with severe obstructive sleep apnea. Sleep Breath. 2012;16:629-37.

[24] Nanas S, Sakellariou D, Kapsimalakou S, Dimopoulos S, Tassiou A, Tasoulis A, et al. Heart rate recovery and oxygen kinetics after exercise in obstructive sleep apnea syndrome. Clin Cardiol. 2010;33:46-51.

[25] Wahlin Larsson B, Kadi F, Ulfberg J, Piehl Aulin K. Skeletal muscle morphology and aerobic capacity in patients with obstructive sleep apnoea syndrome. Respiration. 2008;76:217.

[26] Tryfon S, Stanopoulos I, Dascalopoulou E, Argyropoulou P, Bouros D, Mavrofridis E. Sleep apnea syndrome and diastolic blood pressure elevation during exercise. Respiration. 2004;71:499-504. 
[27] Ozturk LM, Metin G, Cuhadaroglu C, Utkusavas A, Tutluoglu B. Cardiopulmonary responses to exercise in moderate-to-severe obstructive sleep apnea. Tuberk Toraks. 2005;53:10-9.

[28] Alonso-Fernandez A, Garcia-Rio F, Arias MA, Mediano O, Pino JM, Martinez I, et al. Obstructive sleep apnoea-hypoapnoea syndrome reversibly depresses cardiac response to exercise. Eur Heart J. 2006;27:207-15.

[29] Kaleth AS, Chittenden TW, Hawkins BJ, Hargens TA, Guill SG, Zedalis D, et al. Unique cardiopulmonary exercise test responses in overweight middle-aged adults with obstructive sleep apnea. Sleep Med. 2007;8:160-8.

*[30] Hargens TA, Guill SG, Zedalis D, Gregg JM, Nickols-Richardson SM, Herbert WG. Attenuated heart rate recovery following exercise testing in overweight young men with untreated obstructive sleep apnea. Sleep. 2008;31:104-10.

[31] Rizzi CF, Cintra F, Mello-Fujita L, Rios LF, Mendonca ET, Feres MC, et al. Does obstructive sleep apnea impair the cardiopulmonary response to exercise? Sleep. 2013;36:54753.

*[32] Rizzi CF, Cintra F, Risso T, Pulz C, Tufik S, de Paola A, et al. Exercise capacity and obstructive sleep apnea in lean subjects. Chest. 2010;137:109-14.

*[33] Kline CE, Crowley EP, Ewing GB, Burch JB, Blair SN, Durstine JL, et al. Blunted heart rate recovery is improved following exercise training in overweight adults with obstructive sleep apnea. Int J Cardiol. 2013;167:1610-5.

*[34] Cepeda FX, Toschi-Dias E, Maki-Nunes C, Rondon MU, Alves MJ, Braga AM, et al. Obstructive sleep apnea impairs postexercise sympathovagal balance in patients with metabolic syndrome. Sleep. 2015;38:1059-66.

[35] Cintra FD, Tufik S, Paola A, Feres MC, Melo-Fujita L, Oliveira W, et al. Cardiovascular profile in patients with obstructive sleep apnea. Arq Bras Cardiol. 2011;96:293-9. 
[36] Maeder MT, Munzer T, Rickli H, Schoch OD, Korte W, Hurny C, et al. Association between heart rate recovery and severity of obstructive sleep apnea syndrome. Sleep Med. 2008;9:753-61.

[37] Innocenti Bruni G, Gigliotti F, Scano G. Obstructive sleep apnea (OSA) does not affect ventilatory and perceptual responses to exercise in morbidly obese subjects. Respir Physiol \& Neurobiol. 2012;183:193-200.

*[38] Mendelson M, Marillier M, Bailly S, Flore P, Borel JC, Vivodtzev I, et al. Maximal exercise capacity in patients with obstructive sleep apnoea syndrome: A systematic review and meta-analysis. Eur Respir J. 2018; 51: 1702697.

[39] Wells GA, Shea B, O'Connell D, Peterson J, Welch V, Losos M, et al. The NewcastleOttawa Scale (NOS) for assessing the quality of non-randomized studies in meta-analysis. Available from: http://www.ohri.ca/programs/clinical_epidemiology/oxford.asp; 2014.

[40] Gottlieb DJ, Yenokyan G, Newman AB, O'Connor GT, Punjabi NM, Quan SF, et al. Prospective study of obstructive sleep apnea and incident coronary heart disease and heart failure: the sleep heart health study. Circulation. 2010;122:352-60.

[41] Guazzi M, Adams V, Conraads V, Halle M, Mezzani A, Vanhees L, et al. EACPR/AHA Joint Scientific Statement. Clinical recommendations for cardiopulmonary exercise testing data assessment in specific patient populations. Eur Heart J. 2012;33:2917-27.

[42] Jones N, Campbell E. Clinical Exercise testing. Philadelphia. WB: Saunders Co. 1975.

*[43] Stewart LA, Clarke M, Rovers M, Riley RD, Simmonds M, Stewart G, et al. Preferred Reporting Items for Systematic Review and Meta-Analyses of individual participant data: the PRISMA-IPD Statement. JAMA. 2015;313:1657-65.

*[44] Ahmed I, Sutton AJ, Riley RD. Assessment of publication bias, selection bias, and unavailable data in meta-analyses using individual participant data: a database survey. BMJ. 2012;344:d7762. 
[45] Egger M, Davey Smith G, Schneider M, Minder C. Bias in meta-analysis detected by a simple, graphical test. Bmj. 1997;315:629-34.

*[46] Berger M, Barthelemy JC, Hupin D, Raffin J, Dupre C, Labeix P, et al. Benefits of supervised community physical activity in obstructive sleep apnoea. Eur Respir J. 2018;52.

[47] Butner KL, Hargens TA, Kaleth AS, Miller LE, Zedalis D, Herbert WG. Association of obstructive sleep apnea severity with exercise capacity and health-related quality of life. N Am J Med Sci. 2013;5:362-6.

[48] Cavagnolli DA, Esteves AM, Ackel-D'Elia C, Maeda MY, de Faria AP, Tufik S, et al. Aerobic exercise does not change C-reactive protein levels in non-obese patients with obstructive sleep apnoea. Eur J Sport Sci. 2014;14 Suppl 1:S142-7.

[49] Barbosa BT, da Cruz Santos A, Frazao M, Petrucci TR, Cucato GG, Sarmento AO, et al. Obstructive sleep apnea does not impair cardiorespiratory responses to progressive exercise performed until exhaustion in hypertensive elderly. Sleep Breath. 2018;22:431-7.

[50] Chien MY, Chang YJ, Lee P, Yang PC, Wu YT. Electrophysiologic changes with incremental exercise in obstructive sleep apnea. Muscle Nerve. 2013;48:212-8.

[51] Maeder MT, Ammann P, Rickli H, Schoch OD, Korte W, Hurny C, et al. N-terminal proB-type natriuretic peptide and functional capacity in patients with obstructive sleep apnea. Sleep Breath. 2008;12:7-16.

[52] Higgins JP, Thompson SG, Deeks JJ, Altman DG. Measuring inconsistency in metaanalyses. BMJ. 2003;327:557-60.

[53] Harbour R, Miller J. A new system for grading recommendations in evidence based guidelines. BMJ. 2001;323:334-6.

[54] Punjabi NM, Caffo BS, Goodwin JL, Gottlieb DJ, Newman AB, O'Connor GT, et al. Sleepdisordered breathing and mortality: a prospective cohort study. PLoS Med. 2009;6:e1000132. 
[55] Wang X, Ouyang Y, Wang Z, Zhao G, Liu L, Bi Y. Obstructive sleep apnea and risk of cardiovascular disease and all-cause mortality: a meta-analysis of prospective cohort studies. Int J Cardiol. 2013;169:207-14.

[56] McNicholas WT, Bonsignore MR, Levy P, Ryan S. Mild obstructive sleep apnoea: clinical relevance and approaches to management. Lancet Respir Med. 2016;4:826-34.

[57] Iber C, Ancoli-Israel S, Chesson AL, Jr., Quan SF, Medicine AAoS. The AASM manual for the scoring of sleep and associated events: rules, terminology and technical specifications. 1st ed. ed. Westchester, IL: American Academy of Sleep Medicine2007.

[58] Berry RB, Budhiraja R, Gottlieb DJ, Gozal D, Iber C, Kapur VK, et al. Rules for scoring respiratory events in sleep: update of the 2007 AASM Manual for the Scoring of Sleep and Associated Events. Deliberations of the Sleep Apnea Definitions Task Force of the American Academy of Sleep Medicine. J Clin Sleep Med. 2012;8:597-619.

[59] Kokkinos P, Myers J. Exercise and physical activity: clinical outcomes and applications. Circulation. 2010;122:1637-48.

[60] American Thoracic S, American College of Chest P. ATS/ACCP Statement on cardiopulmonary exercise testing. Am J Respir Crit Care Med. 2003;167:211-77.

[61] Javaheri S, Barbe F, Campos-Rodriguez F, Dempsey JA, Khayat R, Javaheri S, et al. Sleep apnea: Types, mechanisms, and clinical cardiovascular consequences. J Am Coll Cardiol. 2017;69:841-58.

[62] Hirotsu C, Haba-Rubio J, Togeiro SM, Marques-Vidal P, Drager LF, Vollenweider P, et al. Obstructive sleep apnoea as a risk factor for incident metabolic syndrome: a joined Episono and Hypnolaus prospective cohorts study. Eur Respir J. 2018; 52:1801150.

[63] Myers J, Prakash M, Froelicher V, Do D, Partington S, Atwood JE. Exercise capacity and mortality among men referred for exercise testing. The New England journal of medicine. 2002;346:793-801. 
*[64] Monico-Neto M, Antunes HKM, Dos Santos RVT, D'Almeida V, de Souza AAL, Bittencourt LRA, et al. Physical activity as a moderator for OSA and cardiometabolic risk in EPISONO study. Eur Respir J. 2018;52:1701972.

[65] Pedersen BK, Saltin B. Exercise as medicine - evidence for prescribing exercise as therapy in 26 different chronic diseases. Scand J Med Sci Sports. 2015;25 Suppl 3:1-72.

[66] Kokkinos P, Myers J, Faselis C, Panagiotakos DB, Doumas M, Pittaras A, et al. Exercise capacity and mortality in older men: a 20-year follow-up study. Circulation. 2010;122:790-7.

[67] Iftikhar IH, Kline CE, Youngstedt SD. Effects of exercise training on sleep apnea: a metaanalysis. Lung. 2014;192:175-84.

*[68] Mendelson M, Bailly S, Marillier M, Flore P, Borel JC, Vivodtzev I, et al. Obstructive sleep apnea syndrome, objectively measured physical activity and exercise training interventions: A systematic review and meta-analysis. Front Neurol. 2018;9:73. 


\section{FIGURE LEGENDS}

Figure 1. PRISMA IPD flow diagram of studies included in the meta-analysis.

Figure 2. Forest plot for subgroup analysis of $\mathrm{VO}_{2 \text { peak }}$ expressed in $\mathrm{mL} \cdot \mathrm{kg}^{-1} \cdot \mathrm{min}^{-1}$ according to individual patient data (IPD) or aggregate data (AD) without adjustment for cofounding factors. The two white diamond reflect the $95 \%$ confidence interval (CI) of the pooled estimate of mean difference for each subgroup while the black diamond reflects the $95 \%$ CI of the overall estimate of mean difference.

Figure 3. Funnel plot for $\mathrm{VO}_{2 \text { peak }}$ expressed in $\mathrm{mLkg}^{-1} \mathrm{~min}^{-1}$ using both individual patient data (IPD) and aggregate data (AD) studies.

Figure 4. Forest plot for subgroup analysis of $\mathrm{VO}_{2 \text { peak }}$ based on $\mathrm{AHI}$ threshold using aggregate data studies. The two white diamond reflect the $95 \%$ confidence interval (CI) of the pooled estimate of mean difference for each subgroup while the black diamond reflects the $95 \%$ CI of the overall estimate of mean difference.

Figure 5. Forest plot for difference in means in $\mathrm{VO}_{2 \text { peak }}$ expressed in $\mathrm{mL} \mathrm{kg}^{-1} \cdot \mathrm{min}^{-1}(\mathrm{~A})$ and in percentage predicted (B) using individual patient data (IPD) adjusted for cofounders.

Figure 6. Forest plot for difference in means in percentage peak heart rate $[\mathrm{HR}]$ predicted (A), HR reserve (B), heart rate recovery one-minute post-exercise [HRR-1] (C), and oxygen pulse (D) using individual patient data (IPD) adjusted for cofounders.

Figure 7. Forest plot for difference in means in peak systolic blood pressure [SBP] (A) and diastolic blood pressure [DBP] (B) using individual patient data (IPD) adjusted for cofounders. 
Table 1. Characteristics of OSA studies included in the IPD and aggregate meta-analysis.

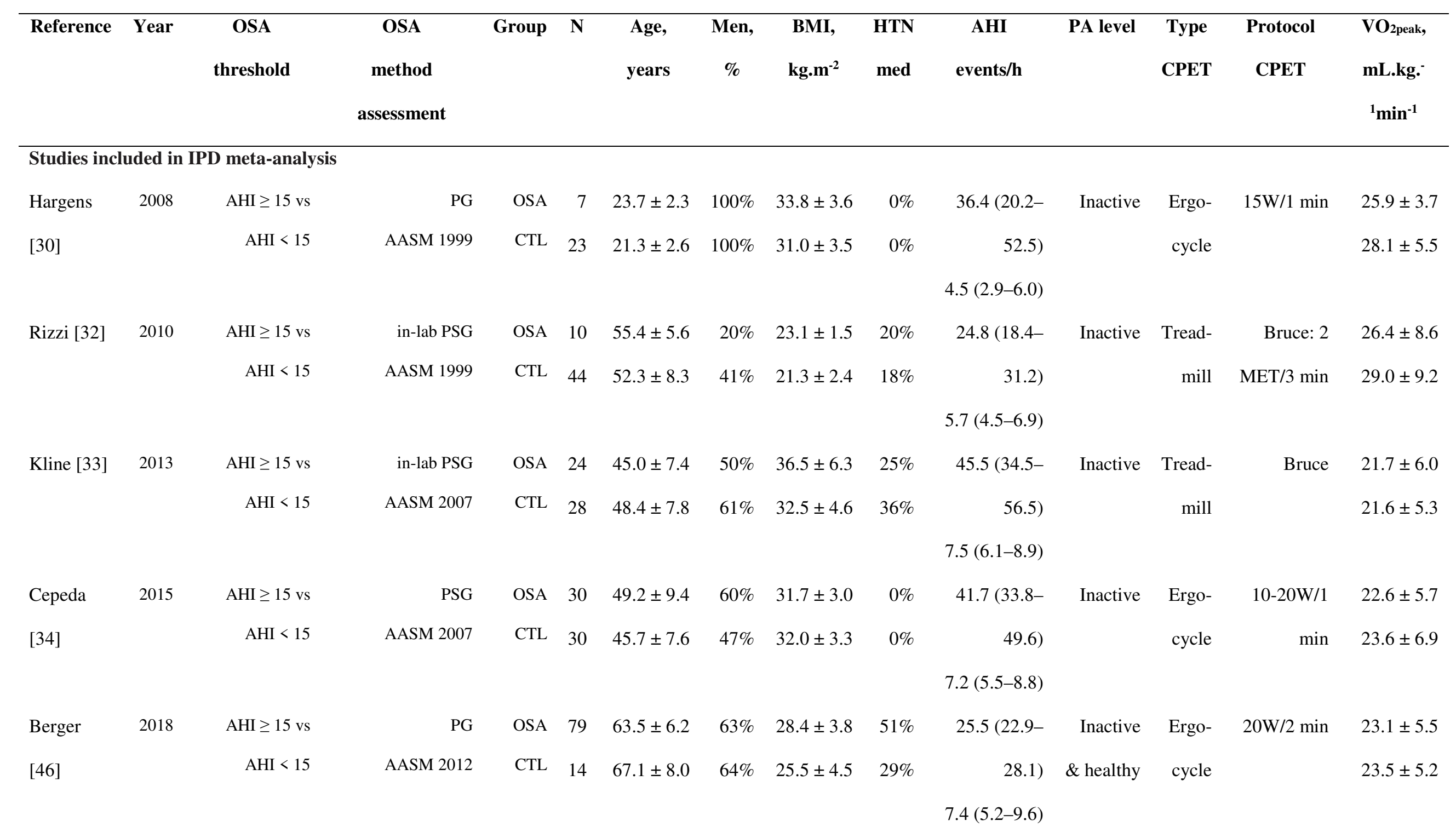




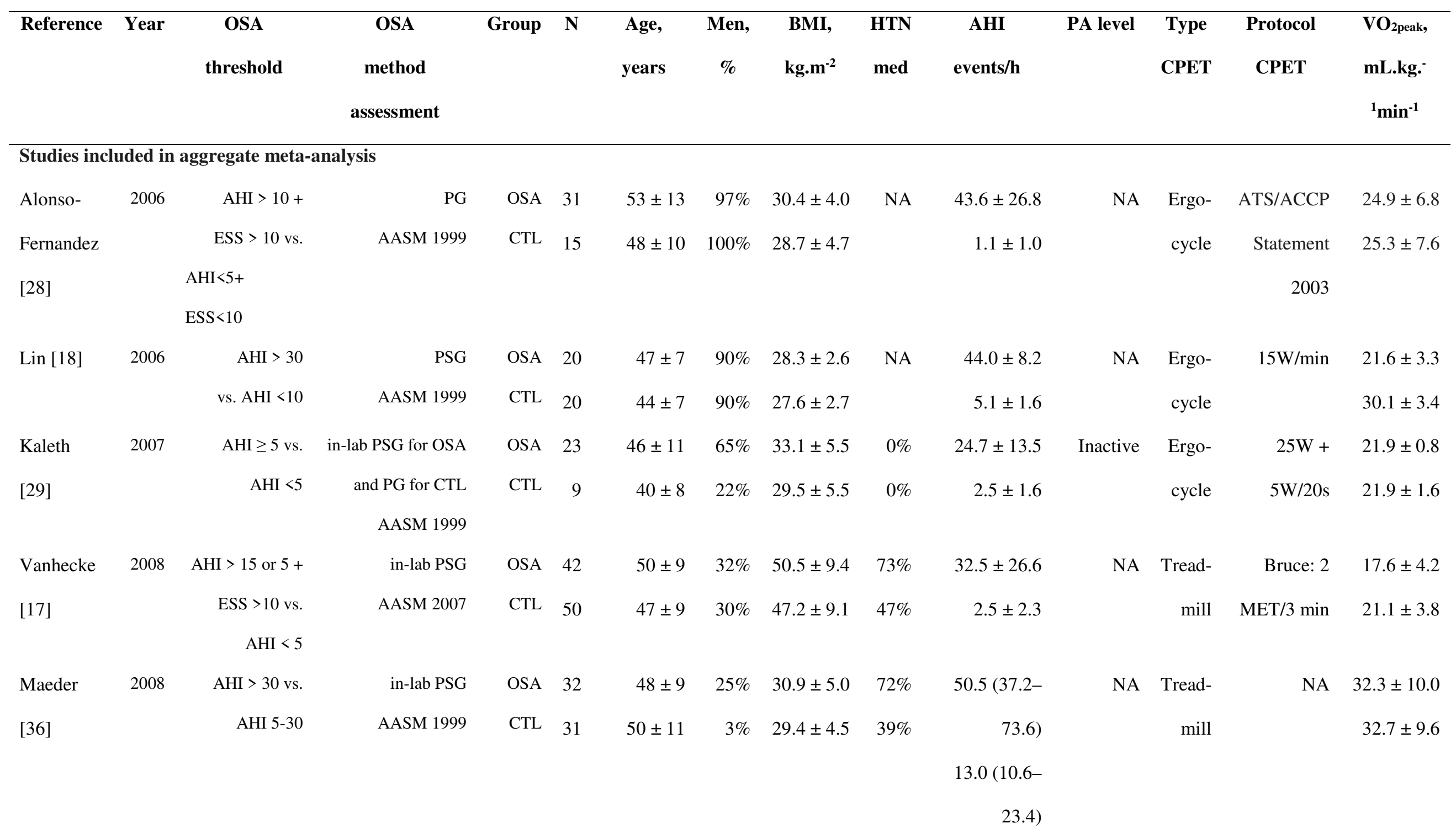




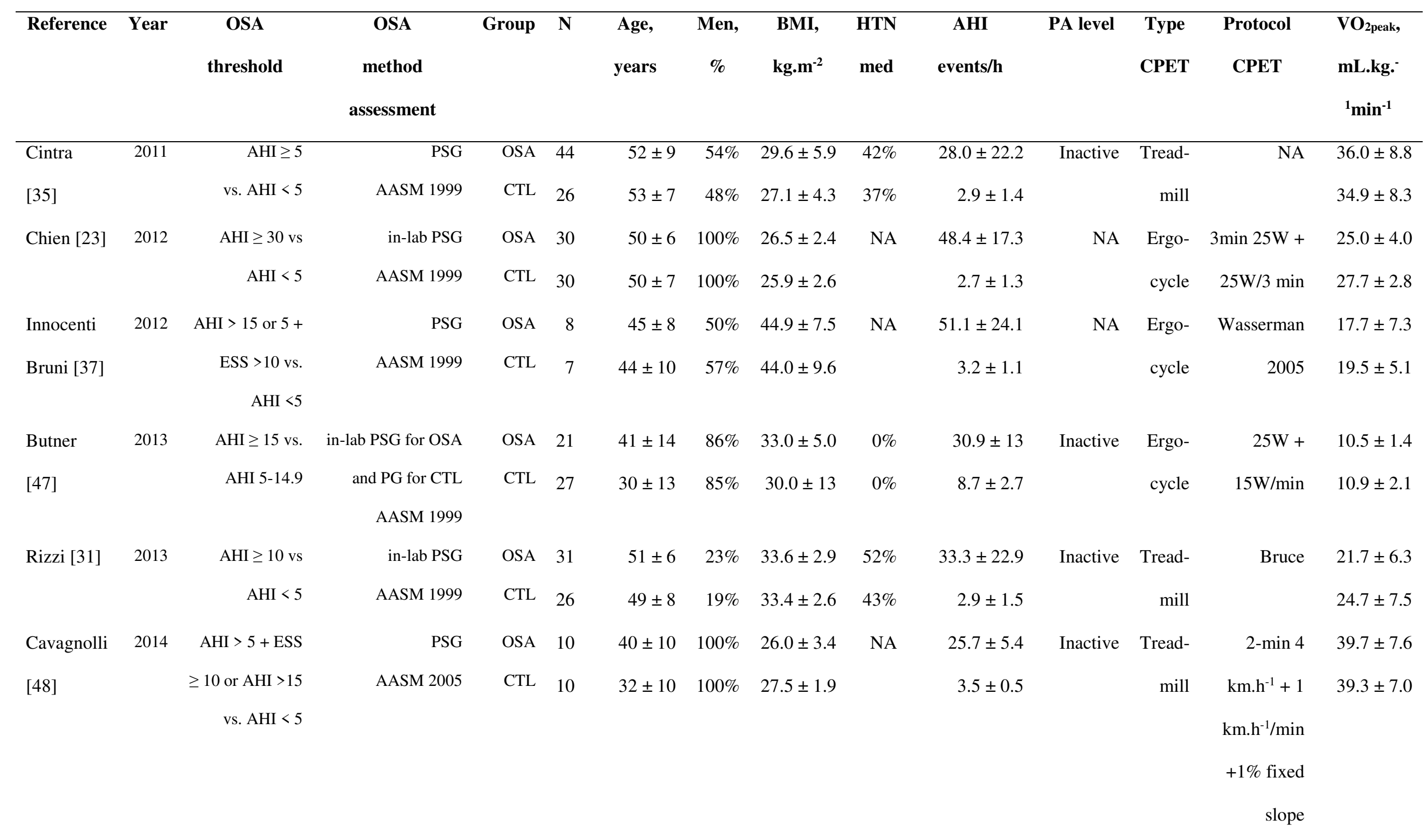




\begin{tabular}{|c|c|c|c|c|c|c|c|c|c|c|c|c|c|c|}
\hline Reference & Year & $\begin{array}{c}\text { OSA } \\
\text { threshold }\end{array}$ & $\begin{array}{c}\text { OSA } \\
\text { method } \\
\text { assessment }\end{array}$ & Group & $\mathbf{N}$ & $\begin{array}{l}\text { Age, } \\
\text { years }\end{array}$ & $\begin{array}{c}\text { Men, } \\
\%\end{array}$ & $\begin{array}{c}\text { BMI, } \\
\text { kg.m² }\end{array}$ & $\begin{array}{l}\text { HTN } \\
\text { med }\end{array}$ & $\begin{array}{c}\text { AHI } \\
\text { events/h }\end{array}$ & PA level & $\begin{array}{l}\text { Type } \\
\text { CPET }\end{array}$ & $\begin{array}{l}\text { Protocol } \\
\text { CPET }\end{array}$ & $\begin{array}{l}\text { VO2peak, } \\
\text { mL.kg.- } \\
{ }^{1} \text { min-1 }^{-1}\end{array}$ \\
\hline Beitler & 2014 & $\mathrm{AHI} \geq 15$ vs. & in-lab PSG & OSA & 15 & $48 \pm 11$ & $80 \%$ & $32.2 \pm 7.8$ & $20 \%$ & $37.6(26.8-$ & Inactive & Ergo- & 1-min $0 \mathrm{~W}+$ & $19.1 \pm 6.4$ \\
\hline [22] & & AHI $<15$ & AASM 2007 & CTL & 19 & $34 \pm 12$ & $53 \%$ & $28.8 \pm 6.5$ & $21 \%$ & $\begin{array}{r}55.3) \\
1.5(0.7-5.4)\end{array}$ & $\&$ healthy & cycle & $\begin{array}{l}10-15 \\
\mathrm{~W} / \mathrm{min}\end{array}$ & $25.2 \pm 9.5$ \\
\hline Barbosa & 2018 & $\mathrm{AHI} \geq 15 \mathrm{vs}$ & in-lab PSG & OSA & 13 & $71 \pm 7$ & $23 \%$ & $26.2 \pm 3.2$ & $58 \%$ & $24.4 \pm 12.6$ & NA & Ergo- & $5-\min 0 \mathrm{~W}+$ & $17.2 \pm 3.7$ \\
\hline [49] & & $\mathrm{AHI}<5$ & AASM 2007 & CTL & 15 & $69 \pm 5$ & $13 \%$ & $27.0 \pm 2.7$ & $54 \%$ & $2.3 \pm 1.5$ & & cycle & $5-10 \mathrm{~W} / \mathrm{min}$ & $16.9 \pm 3.7$ \\
\hline
\end{tabular}

Data are presented as $\%$ or mean \pm SD or $95 \%$ confidence interval in parenthesis. AHI: apnea-hypopnea index; BMI: body mass index; CPET: cardiopulmonary exercise test; CTL: control; ESS: Epworth sleepiness scale; HTN med: hypertension medication; NA: not available; OSA: obstructive sleep apnea; PA: physical activity. 
Table 2. Quality assessment of the included studies in the individual patient data (IPD) and aggregate data (AD) meta-analysis based on a modified version of the Newcastle-Ottawa Scale [38]

\begin{tabular}{|c|c|c|c|c|}
\hline Reference & 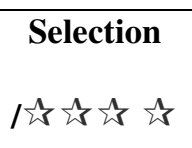 & $\begin{array}{c}\text { Comparability } \\
\text { 放为 }\end{array}$ & $\begin{array}{c}\text { Evaluation } \\
\text { 化放 }\end{array}$ & Total \\
\hline \multicolumn{5}{|c|}{ Studies included in IPD meta-analysis } \\
\hline Hargens [30] & 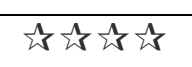 & 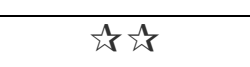 & $\dot{t}$ & 7 \\
\hline Rizzi [32] & 必云办 & $\dot{t} \Delta$ & ts & 6 \\
\hline Kline [33] & 认心引山 & ts & ts & 6 \\
\hline Cepeda [34] & 必云头 & $\dot{\psi} \boldsymbol{t}$ & $\dot{\psi} \boldsymbol{t}$ & 7 \\
\hline Berger [46] & 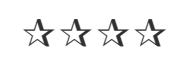 & $\dot{t r}$ & 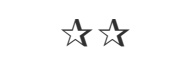 & 7 \\
\hline \multicolumn{5}{|c|}{ Studies included in AD meta-analysis } \\
\hline Alonso-Fernandez [28] & 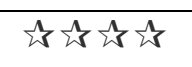 & 交出 & $\dot{H} \vec{t}$ & 8 \\
\hline Lin [18] & 认必视 & 必放 & is & 6 \\
\hline Kaleth [29] & 认必水 & $\dot{t} \Delta$ & ts & 6 \\
\hline Vanhecke [17] & 必老市 & 必考 & ts & 6 \\
\hline Maeder [36] & $\dot{\psi}$ & $\dot{s}$ & 办 & 4 \\
\hline Cintra [35] & 必云头 & $\dot{3}$ & $\dot{s}$ & 5 \\
\hline Chien [23] & 为出主 & 必市 & 为老 & 7 \\
\hline Innocenti Bruni [37] & 认必水 & ts & ts & 5 \\
\hline Butner [47] & 认必水 & ts & ts & 5 \\
\hline Rizzi [31] & 动必放 & 头为 & ts & 6 \\
\hline Cavagnolli [48] & tits & ts & $\dot{t}$ & 4 \\
\hline Beitler [22] & 认必水 & ts & ts & 5 \\
\hline Barbosa [49] & 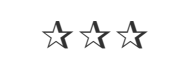 & $\dot{t} \Delta$ & $\dot{t}$ & 6 \\
\hline
\end{tabular}


Figure 1.

\section{PRISMA IPD Flow Diagram}

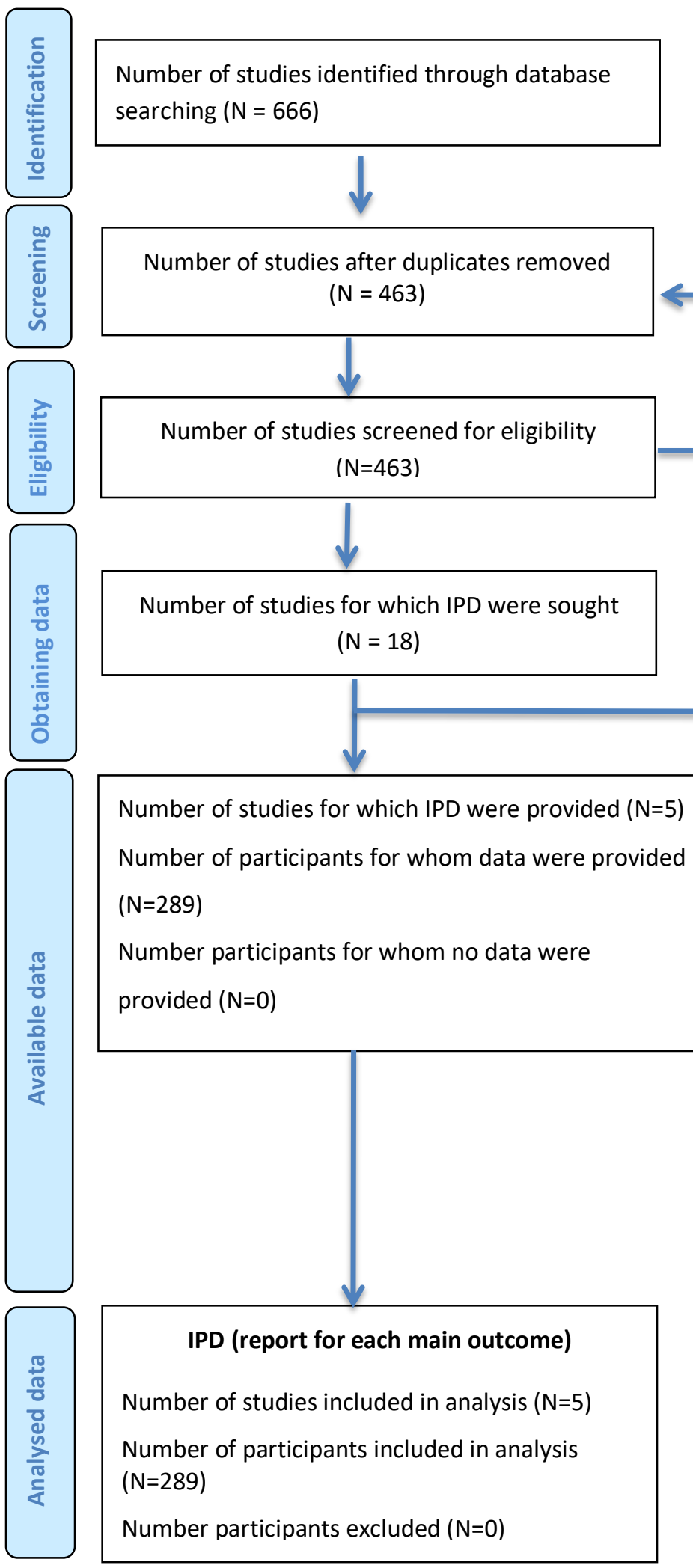

Number of additional studies identified through other sources including contact with researchers $(\mathrm{N}=1)$

Number of studies excluded ( $N=445)$

- after reading titles and abstracts $(\mathrm{N}=428)$

- full-text articles excluded ( $N=17)$

○ $\mathrm{VO}_{2 \text { peak }}$ estimated $(n=6)$

- No control group $(n=5)$

- No sleep recording for controls $(n=4)$

- Anaerobic test $(n=1)$

○ Duplicated results $(n=1)$

Number of studies for which IPD were not provided $(\mathrm{N}=13)$

- Do not answer ( $\mathrm{N}=12)$

- Unable to send their data $(\mathrm{N}=1)$

Number of participants ( $N=605$ )

Number of studies for which aggregate data were available $(\mathrm{N}=13)$

Number of participants $(\mathrm{N}=605)$

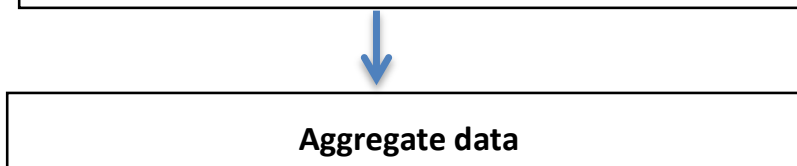

Number of studies included in analysis ( $N=13$ )

Number of participants included in analysis $(N=605)$ Number participants excluded $(\mathrm{N}=0)$ 
Figure 2.

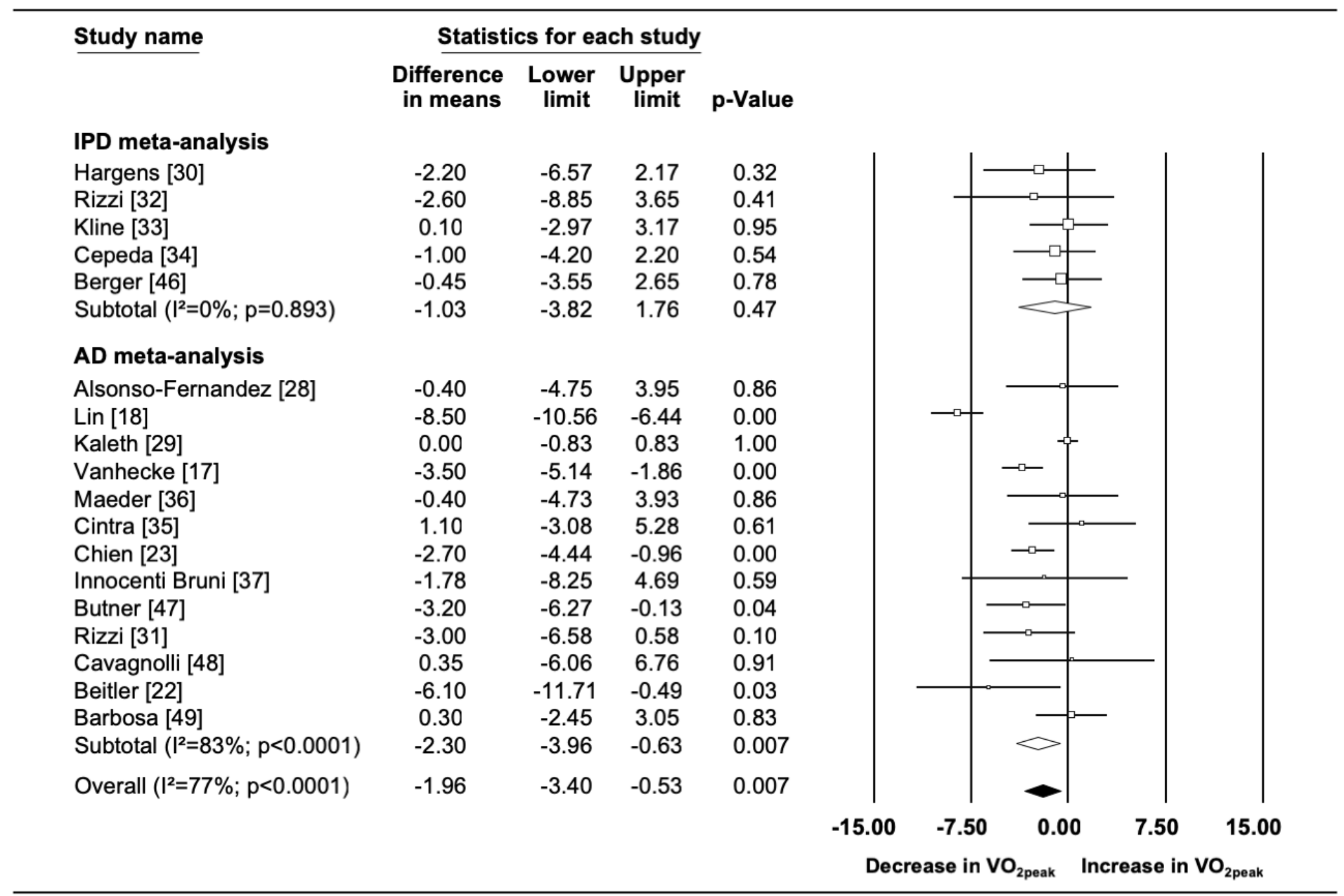




\section{Figure 3.}

\section{Funnel Plot of Standard Error by Difference in means}

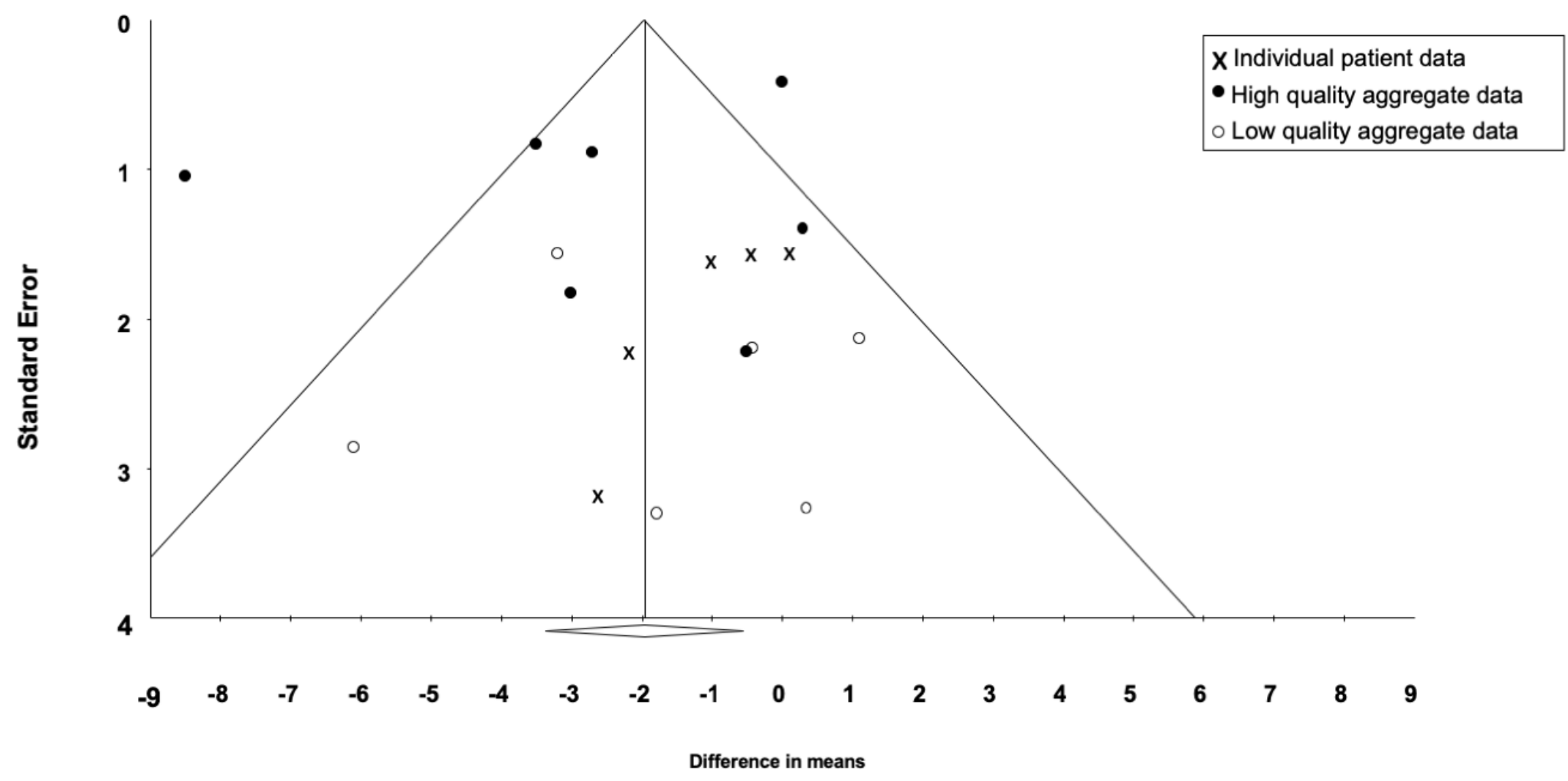


Figure 4.

\section{Study name}

AHI $>5$

Kaleth [29]

Vanhecke [17]

Cintra [35]

Innocenti Bruni [37]

Cavagnolli [48]

Subtotal $\left(I^{2}=73 \% ; p=0.005\right)$

\section{AHI $>10$}

Alsonso-Fernandez [28]

Rizzi [31]

Subtotal $\left(\mathrm{I}^{2}=0 \% ; \mathrm{p}=0.366\right)$

\section{$\mathrm{AHI}>15$}

Butner [47]

Beitler [22]

Barbosa [49]

Subtotal $\left(I^{2}=62 \% ; p=0.071\right)$

AHI $>\mathbf{3 0}$

Lin [18]

Maeder [36]

Chien [23]

Subtotal $\left(I^{2}=91 \% ; p<0.0001\right)$

Overall
Statistics for each study

\begin{tabular}{rrrr}
\cline { 2 - 3 } Difference & Lower & Upper & \\
in means & limit & limit & $p$-Value
\end{tabular}

$\begin{array}{rrrr}0.00 & -0.83 & 0.83 & 1.00 \\ -3.50 & -5.14 & -1.86 & 0.00 \\ 1.10 & -3.08 & 5.28 & 0.61 \\ -1.78 & -8.25 & 4.69 & 0.59 \\ 0.35 & -6.06 & 6.76 & 0.91 \\ -0.94 & -3.75 & 1.86 & 0.51\end{array}$

$\begin{array}{llll}-0.40 & -4.75 & 3.95 & 0.86\end{array}$

$\begin{array}{llll}-3.00 & -6.58 & 0.58 & 0.10\end{array}$

$\begin{array}{llll}-1.80 & -6.33 & 2.73 & 0.44\end{array}$

$\begin{array}{llll}-3.20 & -6.27 & -0.13 & 0.04\end{array}$

$\begin{array}{llll}-6.10 & -11.71 & -0.49 & 0.03\end{array}$

$\begin{array}{llll}0.30 & -2.45 & 3.05 & 0.83\end{array}$

$\begin{array}{llll}-2.48 & -6.09 & 1.13 & 0.18\end{array}$

$\begin{array}{llll}-8.50 & -10.56 & -6.44 & 0.00 \\ -0.40 & -4.73 & 3.93 & 0.86 \\ -2.70 & -4.44 & -0.96 & 0.00 \\ -4.27 & -7.57 & -0.96 & 0.01 \\ -2.34 & -4.42 & -0.26 & 0.03\end{array}$

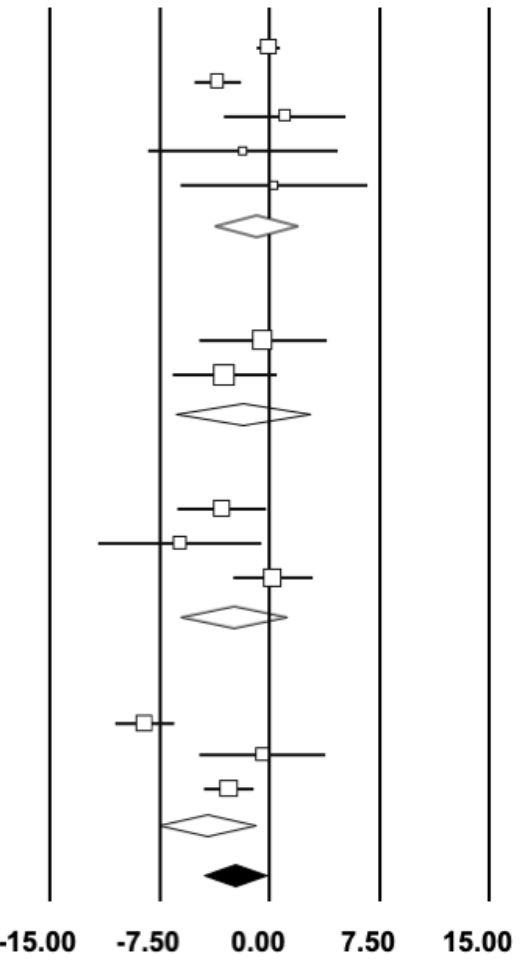

Decrease in $\mathrm{VO}_{2 \text { peak }}$ Increase in $\mathrm{VO}_{2 \text { peak }}$ 


\section{Figure 5.}

A. Study name Statistics for each study

Difference in means and $95 \% \mathrm{Cl}$

\begin{tabular}{|c|c|c|c|c|}
\hline & $\begin{array}{l}\text { Difference } \\
\text { in means }\end{array}$ & $\begin{array}{l}\text { Lower } \\
\text { limit }\end{array}$ & $\begin{array}{r}\text { Upper } \\
\text { limit }\end{array}$ & p-Value \\
\hline Hargens [30] & -1.20 & -5.74 & 3.34 & 0.60 \\
\hline Rizzi [32] & -1.40 & -9.81 & 7.01 & 0.74 \\
\hline Kline [33] & 0.00 & -2.52 & 2.52 & 1.00 \\
\hline Cepeda [34] & -1.10 & -3.38 & 1.18 & 0.34 \\
\hline Berger [46] & -0.50 & -3.25 & 2.25 & 0.72 \\
\hline Overall & -0.65 & -2.01 & 0.70 & 0.35 \\
\hline
\end{tabular}

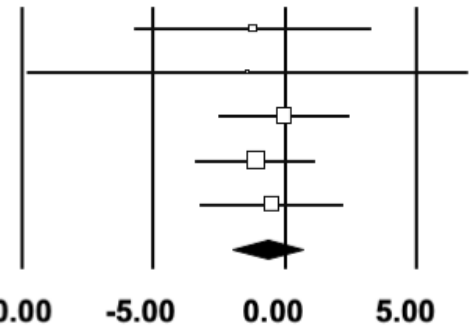

Relative

weight

8.91

2.60

28.96

35.25

24.28

Test for heterogeneity: $l^{2}=0 \%$; Cochran's $Q$ Test: $\mathrm{p}=0.973$

Decrease in $\mathrm{VO}_{2 \text { peak }}{ }^{*}$ Increase in $\mathrm{VO}_{2 \text { peak }}{ }^{*}$

*IPD data were adjusted for age. sex and treated hypertension before pooling in meta-analysis

B. Study name

Statistics for each study

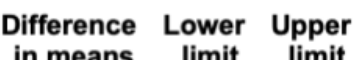

in means limit limit

Hargens [30]

Rizzi [32]

Kline [33]

Cepeda [34]

Berger [46]

Overall

$\begin{array}{rrr}15.00 & -5.10 & 31.10 \\ -8.20 & -33.24 & 16.84 \\ 6.00 & -4.87 & 16.87 \\ -9.00 & -19.38 & 1.38 \\ 6.00 & -5.54 & 17.54 \\ 1.30 & -4.48 & 7.08\end{array}$

p-Value

0.16

0.52

0.28

0.09

0.31

0.66

\section{Difference in means and $95 \% \mathrm{Cl}$}

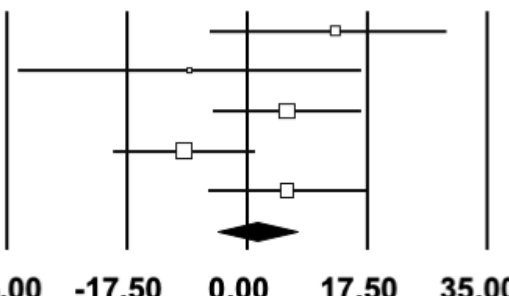

$\begin{array}{lllll}-35.00 & -17.50 & 0.00 & 17.50 & 35.00\end{array}$

Decrease in \% pred Increase in \% pred

$$
\text { VO }_{2 \text { peak }}{ }^{*} \quad \mathrm{VO}_{2 \text { peak }}{ }^{*}
$$

Test for heterogeneity: $I^{2}=45 \%$; Cochran's $Q$ Test: $p=0.121$

*IPD data were adjusted for treated hypertension before pooling in meta-analysis 
Figure 6.

A.

\begin{tabular}{lrrrrr} 
Study name & & \multicolumn{4}{c}{ Statistics for each study } \\
\cline { 3 - 5 } & & $\begin{array}{c}\text { Lifference } \\
\text { in means }\end{array}$ & $\begin{array}{c}\text { Lower } \\
\text { limit }\end{array}$ & $\begin{array}{c}\text { Upper } \\
\text { limit }\end{array}$ & p-Value \\
Hargens [30] & 5.80 & -0.27 & 11.87 & 0.06 \\
Rizzi [32] & -0.80 & -9.54 & 7.94 & 0.86 \\
Kline [33] & 0.30 & -3.97 & 4.57 & 0.89 \\
Cepeda [34] & -3.40 & -6.74 & -0.06 & 0.05 \\
Berger [46] & -1.70 & -7.92 & 4.52 & 0.59 \\
Overall & -0.34 & -3.50 & 2.82 & 0.83
\end{tabular}

Test for heterogeneity: $I^{2}=44 \%$; Cochran's $Q$ Test: $p=0.126$

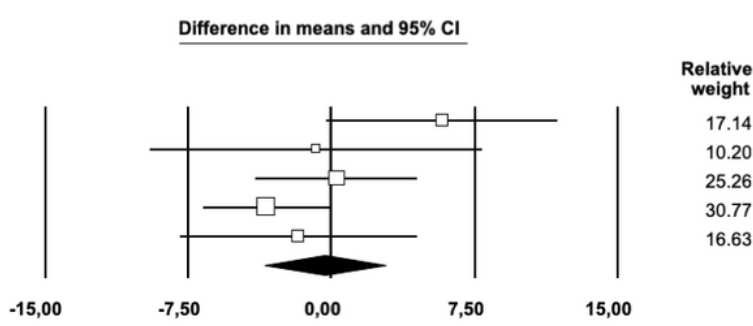

Decrease in \%peak HR pred * Increase in \% peak HR pred *

*IPD data were adjusted for body mass index,sex and treated hypertension before pooling in meta-analysis

B.

\begin{tabular}{lrrrr} 
Study name & \multicolumn{4}{c}{ Statistics for each study } \\
\cline { 2 - 4 } & $\begin{array}{r}\text { Difference } \\
\text { in means }\end{array}$ & $\begin{array}{c}\text { Lower } \\
\text { limit }\end{array}$ & $\begin{array}{r}\text { Upper } \\
\text { limit }\end{array}$ & p-Value \\
Hargens [30] & 1,70 & $-9,73$ & 13,13 & 0,77 \\
Rizzi [32] & 0,30 & $-13,54$ & 14,14 & 0,97 \\
Kline [33] & $-6,30$ & $-15,73$ & 3,13 & 0,19 \\
Cepeda [34] & $-6,50$ & $-13,53$ & 0,53 & 0,07 \\
Berger [46] & 1,30 & $-7,43$ & 10,03 & 0,77 \\
Overall & $-2,97$ & $-7,14$ & 1,20 & 0,16
\end{tabular}

Test for heterogeneity: $I^{2}=0 \%$; Cochran's $Q$ Test: $p=0.521$

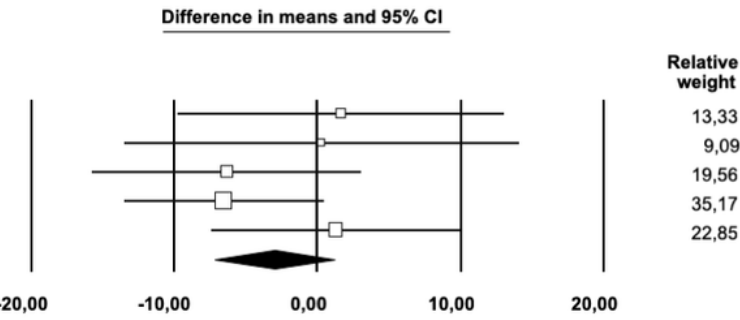

Decrease in HR reserve * Increase in HR reserve *

*IPD data were adjusted for age, sex, body mass index and treated hypertension before pooling in meta-analysis

C. Study name Statistics for each study

\begin{tabular}{|c|c|c|c|c|}
\hline \multirow{2}{*}{ Study name } & \multicolumn{4}{|c|}{ 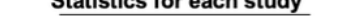 } \\
\hline & $\begin{array}{l}\text { Difference } \\
\text { in means }\end{array}$ & $\begin{array}{c}\text { Lower } \\
\text { limit }\end{array}$ & $\begin{array}{c}\text { Upper } \\
\text { limit }\end{array}$ & p-Value \\
\hline Hargens [30] & -10.60 & -19.13 & -2.07 & 0.01 \\
\hline Rizzi [32] & 4.70 & -3.15 & 12.55 & 0.24 \\
\hline Kline [33] & -5.00 & -9.54 & -0.46 & 0.03 \\
\hline Cepeda [34] & -0.70 & -4.60 & 3.20 & 0.72 \\
\hline Berger [46] & -4.20 & -9.81 & 1.41 & 0.14 \\
\hline Overall & -2.79 & -5.18 & -0.41 & 0.02 \\
\hline
\end{tabular}

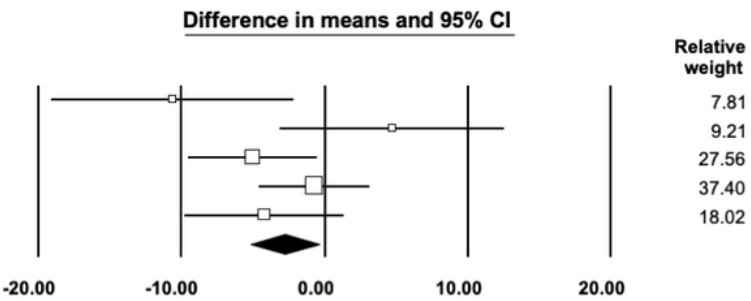

Test for heterogeneity: ${ }^{2}=55 \%$; Cochran's $Q$ Test: $p=0.062$

Decrease in HRR-1 * Increase in HRR-1 *

*IPD data were adjusted for age, sex, body mass index and treated hypertension before pooling in meta-analysis

D. Study name Statistics for each study

Difference in means and $95 \% \mathrm{Cl}$

$\begin{array}{lrrrr} & \begin{array}{c}\text { Difference } \\ \text { in means }\end{array} & \begin{array}{c}\text { Lower } \\ \text { limit }\end{array} & \begin{array}{c}\text { Upper } \\ \text { limit }\end{array} & \text { p-Value } \\ \text { Hargens [30] } & -1,00 & -3,38 & 1,38 & 0,41 \\ \text { Rizzi [32] } & 0,80 & -1,81 & 3,41 & 0,55 \\ \text { Kline [33] } & 0,60 & -0,73 & 1,93 & 0,38 \\ \text { Cepeda [34] } & -0,80 & -2,34 & 0,74 & 0,31 \\ \text { Berger [46] } & 2,00 & 0,50 & 3,50 & 0,01 \\ \text { Overall } & 0,40 & -0,73 & 1,53 & 0,49\end{array}$

Test for heterogeneity: ${ }^{2}=51 \%$; Cochran's $Q$ Test: $p=0.086$

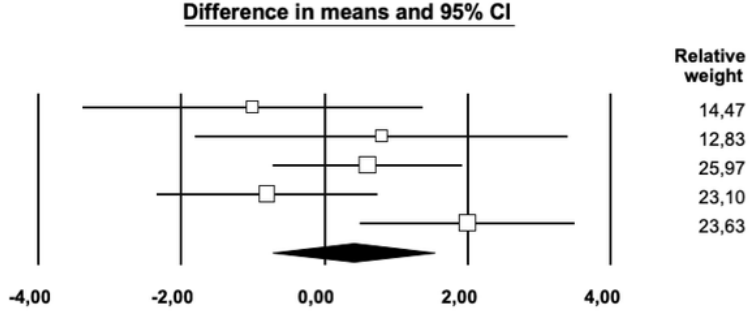

Decrease in 02 pulse *

Increase in 02 pulse * 
Figure 7.

\begin{tabular}{llrrrr} 
A. Study name & & \multicolumn{4}{c}{ Statistics for each study } \\
\cline { 3 - 6 } & & $\begin{array}{r}\text { Difference } \\
\text { in means }\end{array}$ & $\begin{array}{r}\text { Lower } \\
\text { limit }\end{array}$ & $\begin{array}{c}\text { Upper } \\
\text { limit }\end{array}$ & p-Value \\
Hargens [30] & -4.00 & -30.35 & 22.35 & 0.77 \\
Rizzi [32] & -4.50 & -22.04 & 13.04 & 0.62 \\
Kline [33] & -4.00 & -18.40 & 10.40 & 0.59 \\
Berger [46] & 10.00 & -6.92 & 26.92 & 0.25 \\
Overall & -0.36 & -9.13 & 8.41 & 0.94
\end{tabular}

Test for heterogeneity: ${ }^{2}=0 \%$; Cochran's $Q$ Test: $p=0.578$

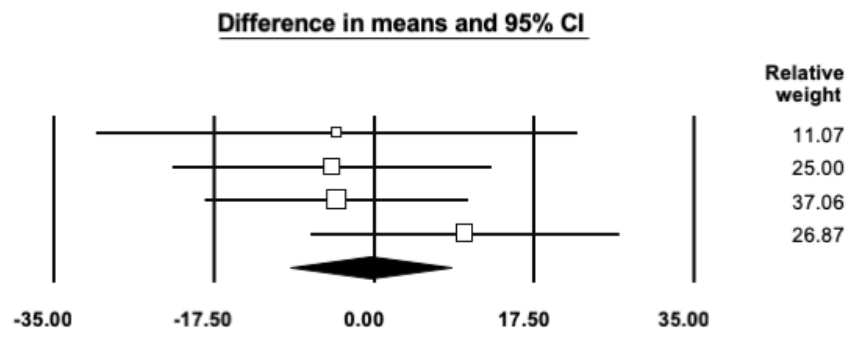

Decrease in peak SBP * Increase in peak SBP *

"IPD data were adjusted for age. sex. body mass index and treated hypertension before pooling in meta-analysis

B.

\begin{tabular}{lrrrr} 
Study name & & \multicolumn{4}{c}{ Statistics for each study } \\
\cline { 3 - 5 } & $\begin{array}{rrrrr}\text { Difference } \\
\text { in means }\end{array}$ & $\begin{array}{r}\text { Lower } \\
\text { limit }\end{array}$ & $\begin{array}{c}\text { Upper } \\
\text { limit }\end{array}$ & p-Value \\
Hargens [30] & -2.20 & -13.32 & 8.92 & 0.70 \\
Rizzi [32] & -1.60 & -12.66 & 9.46 & 0.78 \\
Kline [33] & 2.10 & -5.97 & 10.17 & 0.61 \\
Berger [46] & -3.60 & -12.20 & 5.00 & 0.41 \\
Overall & -1.05 & -5.76 & 3.66 & 0.66
\end{tabular}

Test for heterogeneity: I $^{2}=0 \%$; Cochran's $Q$ Test: $p=0.808$

Difference in means and $95 \% \mathrm{Cl}$

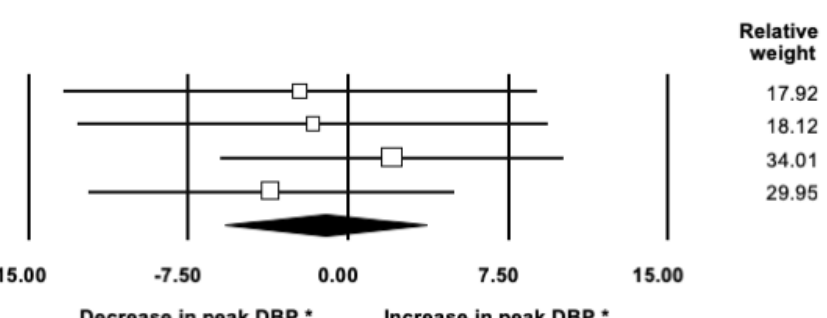

Decrease in peak DBP * Increase in peak DBP *

"IPD data were adjusted for age, sex, body mass index and treated hypertension before pooling in meta-analysis 